\title{
MODELLING DAMAGE GROWTH USING A PHYSICALLY-BASED AND FINITE DEFORMATION MODEL
}

\author{
Sérgio Costa $^{1 *}$, Hana Zrida ${ }^{2}$, Miguel Herraez ${ }^{3}$, Robin Olsson $^{1}$ and Rickard Östlund ${ }^{2}$ \\ ${ }^{1}$ RISE SICOMP AB, Box 104, SE-431 22 Mölndal, Sweden. *sergio.costa@ri.se \\ ${ }^{2}$ Gestamp Hardtech AB, Luleå, Sweden. ${ }^{3}$ Materials Science and Engineering Area, University Rey \\ Juan Carlos, c/Tulipán s/n, Móstoles, 28933, Madrid, Spain.
}

A mesoscale model for fibre kinking [2] is merged with a model for matrix fracture [1]. The fibre kinking behaviour is based on fibre kinking theory and finite deformation. The nonlinear behaviour is pressure dependent and is modelled by combining damage and friction on the fracture plane. The damage and fibre rotation due to kinking growth affects the transverse behaviour and vice-versa. The model shows efficiency considering the high complexity mechanisms involved. For verification the model is tested against micro-mechanical FE simulations with multi-axial stress states such as $\sigma_{22}-\sigma_{11}$ and $\tau_{12}-\sigma_{11}$ and against selected component tests. The combination of both models results in a high definition and physically-based 3D constitutive model for damage growth and crash of composite materials.
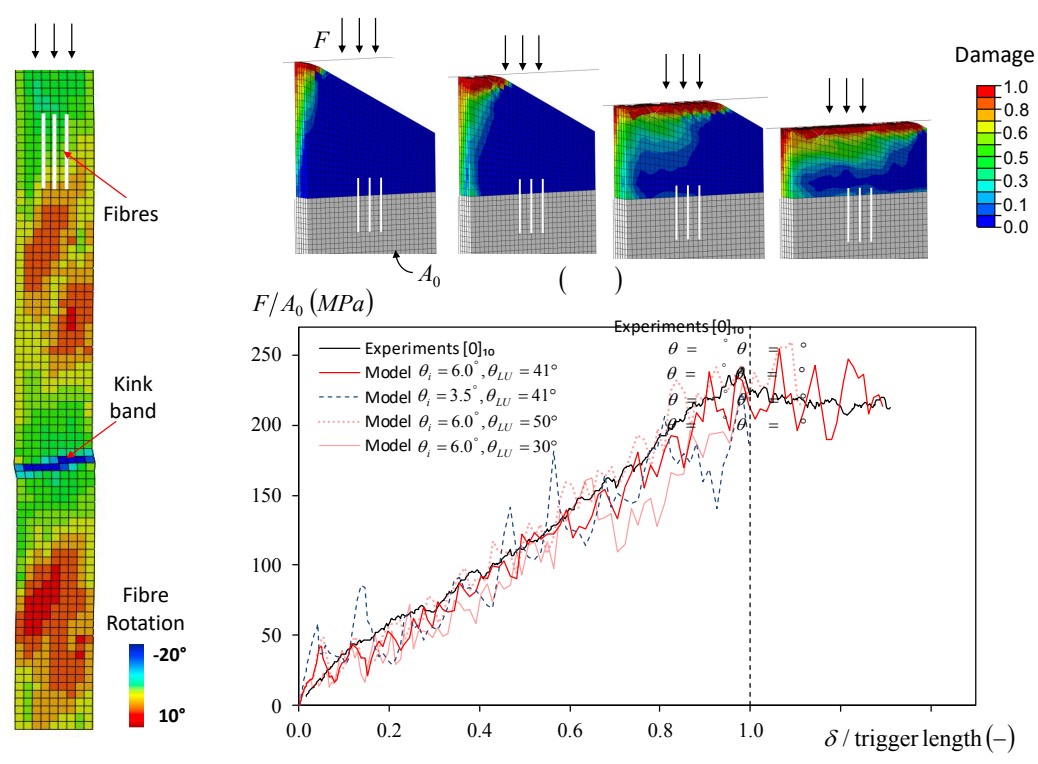

Figure 1: Left: Model predictions of spatial distributions of kink-band formation under compressive load. Right: Experimental vs. numerical crushing response for different fibre misalignments and lock-up angles.

\section{References}

[1] S. Costa, T. Bru, R. Olsson and A. Portugal (2019) Improvement and validation of a physically based model for the shear and transverse crushing of orthotropic composites. Journal of Composite Materials, 53, 1681-1696.

[2] S. Costa, M. Fagerström and R. Olsson (2020) Development and validation of a finite deformation fibre kinking model for crushing of composites. Composites Science and Technology, 197, 108236. 